\title{
Therapeutics
}

\section{Magnesium sulphate prevented eclampsia in women with pre-eclampsia}

The Magpie Trial Collaborative Group. Do women with pre-eclampsia, and their babies, benefit from magnesium sulphate? The Magpie Trial: a randomised placebo-controlled trial. Lancet 2002;359:1877-90.

\section{QUESTION: In women with pre-eclampsia, does magnesium sulphate reduce the risk of eclampsia and improve pregnancy outcome?}

\section{Design}

Randomised (allocation concealed*), blinded (clinicians, patients, data collectors, and data analysts),* placebo controlled trial with follow up to discharge from hospital after delivery (MAGnesium sulphate for Prevention of Eclampsia [MAGPIE] Trial).

\section{Setting}

175 hospitals in 33 countries.

\section{Patients}

10141 women who had not yet given birth or had delivered within $<24$ hours, had pre-eclampsia (diastolic blood pressure $[\mathrm{BP}] \geq 90 \mathrm{~mm} \mathrm{Hg}$, systolic $\mathrm{BP} \geq 140$ $\mathrm{mm} \mathrm{Hg}$ on $\geq 2$ occasions, and proteinuria $\geq 1+$ ), and clinical uncertainty existed about the use of magnesium sulphate. Exclusion criteria were hypersensitivity to magnesium, hepatic coma with risk of renal failure, or myasthenia gravis. $99.7 \%$ of women were included in the analysis.

\section{Intervention}

Women were allocated to magnesium sulphate $(\mathrm{n}=5071)$ or placebo $(n=5070)$. Magnesium sulphate could be given intravenously (IV) or intramuscularly (IM). Standard treatment was a loading dose of $8 \mathrm{ml} \mathrm{(4} \mathrm{g}$ of magnesium sulphate) followed by 24 hour maintenance therapy of $2 \mathrm{ml} /$ hour (IV) (1 g/hour magnesium sulphate or placebo) or two $10 \mathrm{ml}$ IM injections (5 g magnesium sulphate or placebo) (1 into each buttock) and $10 \mathrm{ml}$ every 4 hours. An eclampsia rescue pack was included in each treatment pack in case of eclamptic seizure.

\section{Main outcome measures}

Eclampsia and death of the baby before hospital discharge (including stillbirths). Secondary outcomes were maternal death and a composite outcome of serious maternal morbidities.

\section{Main results}

Analysis was by intention to treat. Fewer women who received magnesium sulphate had eclampsia than did women who received placebo (table). For the 8775 women who were randomised before delivery, the groups did not differ significantly for death of the infant (table). The groups did not differ for maternal death or serious maternal morbidities (table)

\section{Conclusion}

In women with pre-eclampsia, magnesium sulphate reduced the risk of eclampsia, but did not significantly improve other pregnancy outcomes

*See glossary.
Sources of funding:

UK Medical Research

Council; UK

Department for

International

Development;

UNDP/UNFPA/WHO/World

Bank Special

Programme of

Research, Development and Research Training

in Human

Reproduction

For correspondence: Dr L Duley, Resource Centre for Randomised Trials, Oxford, UK.

lelia.duley@ndm.ox.ac.uk

Magnesium sulphate $v$ placebo to prevent eclampsia $†$

\begin{tabular}{lclll}
$\begin{array}{l}\text { Outcomes at } \\
\text { hospital discharge }\end{array}$ & $\begin{array}{c}\text { Magnesium } \\
\text { sulphate }\end{array}$ & Placebo & RRR (95\% Cl) & NNT (Cl) \\
\hline Eclampsia & $0.8 \%$ & $1.9 \%$ & $58 \%(40$ to 71$)$ & 91 (63 to 143$)$ \\
\hline Maternal death & $0.2 \%$ & $0.4 \%$ & $45 \%(-14$ to 74$)$ & Not significant \\
& $12.7 \%$ & $12.4 \%$ & $2 \%(-8$ to 14$)$ & Not significant \\
\hline $\begin{array}{l}\text { Infant death } \\
\text { Any serious maternal } \\
\text { morbidities }\end{array}$ & $3.9 \%$ & $3.6 \%$ & $7.1 \%(-30$ to 12$) \ddagger$ & Not significant \\
\hline
\end{tabular}

tAbbreviations defined in glossary.

$\ddagger$ Calculated from data in article.

\section{COMMENTARY}

In 1995 , the Eclampsia trial ${ }^{1}$ showed that magnesium sulphate was superior to diazepam or phenytoin in reducing the prevalence of recurrent eclamptic seizures. This group of investigations and collaborators has now logically moved from treatment to prevention of the primary eclamptic episode. The MAGPIE trial showed that magnesium sulphate was effective regardless of severity of pre-eclampsia, gestational age at trial entry, or whether delivery had occurred. In the Magpie trial and the earlier Eclampsia trial, maternal mortality was reduced but failed to reach statistical significance; however, future meta-analysis will improve power in this regard. Neither study showed any effect on perinatal mortality.

Magnesium sulphate was not effective in reducing the eclamptic rate in countries with a low perinatal mortality rate. It must be noted, however, that less severe cases were involved in these countries and the sample size was small.

The safety of magnesium sulphate at the trial doses is now beyond dispute having been given in several healthcare situations to thousands of participants. Given its safety, effectiveness, and low cost, it is imperative that a concerted effort be made to educate healthcare workers and to make this intervention available to every facility caring for pregnant women. In areas where magnesium sulphate is already used extensively, investigators might want to adjust dosing schedules or run trials to determine if a different dose brings more benefit. One major question concerns the inclusion of participants receiving anticonvulsive interventions before randomisation (approximately $9 \%$ ). These interventions were, however, equally distributed between magnesium sulphate and placebo groups. Magnesium sulphate showed no effect in this group of patients when analysed separately, but this lack of difference may be a factor of sample size rather than noneffectiveness or dampening effect of the loading dose of magnesium sulphate.

Robert Burrows, MD

Monash Medical Centre Clayton, Victoria, Australia

1 Which anticonvulsant for women with eclampsia? Evidence from the Collaborative Eclampsia Trial. Lancet 1995;345:1455-63. 